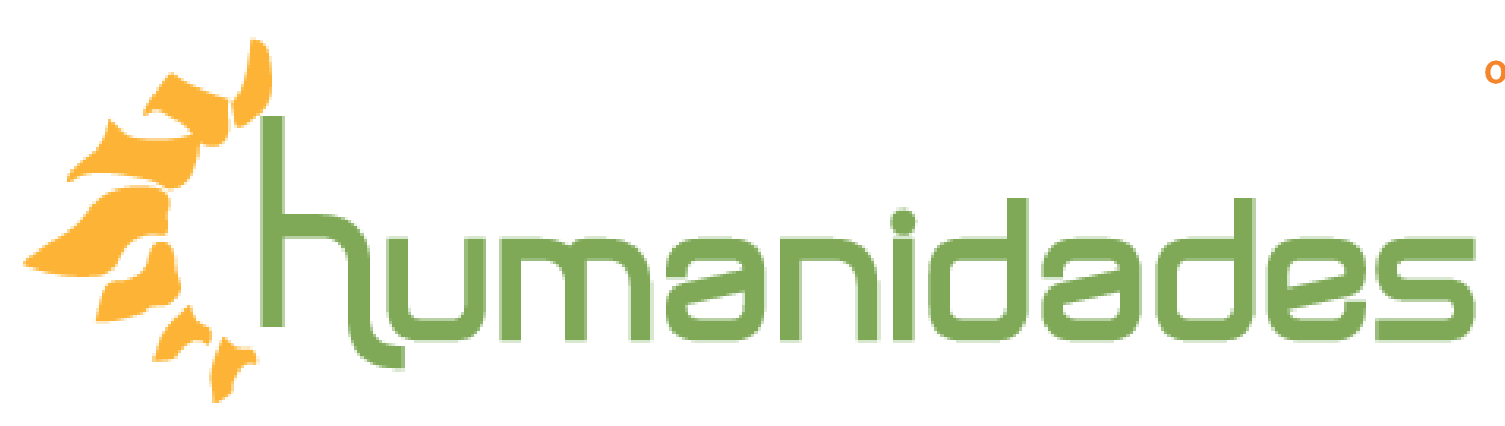

Revista de la Escuela de Estudios Generales, Universidad de Costa Rica

Enero-junio, 2018 •Volumen 8, número 1 • EISSN 2215-3934•pp. 121-136

Recibido: 25-Octubre-2017 Aceptado:29-Noviembre-2017

\title{
La posibilidad de creencias religioso-regionales. Una aproximación desde el significado de la religión católi- ca en el Occidente de México
}

DOI: http://dx.doi.org/10.15517/h.v8i1.31865

\section{Dr. Domingo Coss y León}

Escuela de Humanidades y Educación Región Occidente,

Tecnológico de Monterrey en Guadalajara, México

Correo electrónico: domingo.coss@itesm.mx

\section{Dr. José Carlos Vázquez Parra}

Escuela de Humanidades y Educación Región Occidente,

Tecnológico de Monterrey en Guadalajara, México

Correo electrónico:jcvazquezp@itesm.mx

Todos los derechos reservados. Universidad de Costa Rica. Esta revista se encuentra licenciada con Creative Commons. Reconocimiento-NoComercial-SinObraDerivada 3.0 Costa Rica. Correo electrónico: humanidades@ucr.ac.cr / Sitio web: http://revistas.ucr.ac.cr/index.php/ humanidades 


\title{
La posibilidad de creencias religioso-regionales. Una aproximación desde el significado de la religión católica en el Occidente de México
}

\section{Resumen}

Cuando hablamos de creencias religiosas, es usual que hagamos referencia a un sistema ideológico por medio del cual un individuo se relaciona con su Dios. Sin embargo, hay algunos de estos códigos morales que consiguen trascender del terreno plenamente espiritual, influyendo de manera muy considerable en la forma en que los individuos se comportan o deciden en la sociedad. El presente artículo busca exponer la posibilidad de creencias de tipo religioso-regionales, las cuales un individuo de una cierta población o ciudad adopte como parte de su forma de ser y elegir, o incluso, como una característica propia de pertenencia, más allá del sentido exclusivamente religioso.
Palabras claves: Iglesia, Dios, Racionalidad, Personalidad, Decisiones.

\section{The possibility of religious-regional beliefs. An approxi- mation from the meaning of the Catholic religion in the West of Mexico}

\begin{abstract}
When we speak of religious beliefs, it is usual to refer to an ideological system through which an individual relates to his God. However, there are some of these moral codes that transcend the fully spiritual terrain, greatly influencing how individuals behave or decide in society. This article seeks to expose the possibility of religious and regional beliefs, which an individual from a certain population or city adopts as part of their way of being and choose, or even as a characteristic of belonging, beyond meaning exclusively religious.
\end{abstract}

Keywords: Church, God, Rationality, Personality, Decisions 
La posibilidad de creencias religioso-regionales...

Desde su fundación en 1548, la diócesis de Guadalajara ejerció el control sobre un extenso territorio que abarcaba el occidente y norte de la Nueva España. Sin embargo, el Reino de Nueva Galicia fue el centro desde el cual irradiaban los esfuerzos por implantar un catolicismo acendrado. Fue tan fuerte la huella dejada por la evangelización y la asimilación del catolicismo en esta zona, que incluso se le ha considerado un factor importante que dotó, a finales de la época colonial, de conciencia regional y orgullo a toda la elite de la zona (González, 1983).

Fue hasta el año de 1863 cuando recibió el nombre de Arquidiócesis abarcando los actuales estados de Nayarit, Jalisco, Aguascalientes, Colima, Guanajuato y Michoacán. Así pues, Guadalajara se consolidó desde entonces como la capital eclesiástica del occidente de México, región considerada como uno de los centros católicos más importantes del país e incluso, del mundo (De la Torre, 2002). Además, la Arquidiócesis cuenta con tres de los centros de peregrinaje más importantes de México: San Juan de los Lagos, Talpa y Zapopan, cuyos santuarios anualmente convocan a millones de peregrinos de sus localidades y del resto del país.

Esta región también se ha distinguido por ser un semillero de vocaciones desde la época colonial, en parte porque las familias acomodadas acostumbraban enviar a los hijos a estudiar a los seminarios, y algunos continuaban su carrera de sacerdotes (De la Mora, 2002: 46). Esta herencia cultural aún prevalece y explica el hecho de la construcción de seminarios, así como de múltiples templos y colegios que han fortalecido la infraestructura eclesial de la Arquidiócesis (Bauer, 1986).

Por otra parte, la defensa de la religión católica frente a los embates del Estado moderno ha tenido por escenario también al occidente mexicano. Desde las reformas borbónicas en el siglo XVIII, y principalmente a partir de la independencia, la iglesia católica se ha visto enfrentada a los impulsos liberales que han intentado disminuir su poder e influencia (Miranda, 2007). El más reciente conflicto Iglesia-Estado en la década de los veinte del siglo pasado levantó en armas a miles de católicos en defensa de la fe, dejando una huella importante en la conciencia regional católica, lo cual se ha visto reforzado en las últimas fechas por la canonización de algunos “mártires cristeros” de la zona (De la Torre, 2002: 61). 
En partes de la zona Alta del estado de Jalisco, la verdade-

ra revolución mexicana fue la cristera, realzando la importancia de la religión sobre las cuestiones civiles o de gobierno. Considerando este pasado, y la importancia histórica del arquidiócesis de occidente para la religión católica, el presente artículo busca hacer una aproximación, desde una metodología de análisis bibliográfico, sobre la manera en que la iglesia parece mantener su supremacía ideológica en ciertas zonas de México, haciendo un abordaje a partir de un estudio de caso concreto, el occidente mexicano. Esto pretende mostrar cómo esta identidad religiosa no solo se constituye como una forma de religarse con Dios, sino incluso como sistema de creencia valido para el actuar y vivir de sus fieles (Bautista, 2005).

Para llegar a este punto de análisis, primeramente, se hará un abordaje de los nuevos retos que viven las religiones ante un presente cosmopolita y globalizado, considerando como esta nueva realidad ha llevado al desmoronamiento del bastión religioso. Sin embargo, esto también permitirá comprender como esto realmente no impacta de la misma forma a todas las regiones de México, siendo la zona occidente, aún el sitio predilecto de la iglesia católica. El presente artículo, pretende explicar cómo el rol tan fortalecido que desempeña la Iglesia mexicana de occidente, ha contribuido a que las creencias de sus fieles sigan viendo en la religión católica la alternativa más fuerte, aunque, en muchas ocasiones no resulte ser la más óptima o racional

\subsection{La identidad religiosa ante las transformaciones mundiales ac- tuales.}

Con toda esta herencia histórica de casi cinco siglos a cuestas, la iglesia católica de Guadalajara enfrenta hoy día nuevos retos en una realidad de profundos cambios mundiales y de una nueva pluralidad religiosa (Connaughton, 1992). En los últimos veinte años, y coincidiendo con el declive de las ideologías anunciado por el posmodernismo, la región ha sido testigo de una diversificación de religiones y ofertas de ideologías que se multiplican en el mercado de lo religioso desregularizado, donde florecen espacios, no necesariamente religiosos, en los que la gente puede buscar y reencontrar el sentido de sus vidas (De la Mora, 1995). En el marco de estos movimientos, se pueden vislumbrar tres procesos simultáneos que han contribuido al estallido de lo religioso: la secularización de la sociedad, la globalización y el individualismo contemporáneo. 
La posibilidad de creencias religioso-regionales...

En cuanto a la globalización, se puede entender que esto va más allá de una cuestión política o económica, ya que este fenómeno contemporáneo trae, a la par, una gran posibilidad de acceso a información por medio de las tecnologías de la información. El internet, ha permitido utilizar la infraestructura global para generar nuevas redes de comunicación, con las cuales el pensamiento de uno llega a viralizarse en millones de nuevos comentarios, abriendo espacios de opinión y análisis tan amplios, inclusivos y diversos, como nunca antes se había tenido. La idea del libre mercado globalizador parece venir aparejado a un espacio de libertad ideológica y de creencias en un espacio global de bienes simbólicos.

Así pues, en la red se pueden encontrar desde comunidades minoritarias de aventureros de la fe hasta sitios de las grandes religiones estructuradas por un clero como la católica. De este modo, el Internet se ha convertido en un terreno privilegiado de evangelización y de batallas ideológico-religiosas por la conquista de las almas (Vi1lar, 2001). La iglesia católica mundial, y en particular la de México, conscientes de ésta nueva realidad, hacen uso ya de éstos nuevos espacios en una evidente competencia por la preeminencia mundial y local, así como de la conservación de los fieles.

En esta nueva situación mundial, el individuo, inmerso en una sociedad informatizada y con una oferta simbólica sin restricciones, juega cada vez un papel más importante en la producción de sentido (De la Mora, 2002). El eclipse o la desaparición de la religión como sistema de creencias único da pauta a un nuevo modelo individualista de creencias, privilegiando una religiosidad en la que el individuo toma para sí elementos diversos de las múltiples ofertas religiosas en una búsqueda personal de construcción simbólica de la fe (Bárcenas, 2014).

Se da así una primacía de la función instrumental de lo religioso, en la que el cristianismo, en general, ha tenido un desplazamiento hacia el protestantismo con la evolución propia de un individualismo en detrimento de las funciones colectivas. Cada vez es más evidente la situación en la que el individuo no siente la necesidad de una mediación entre él y la divinidad, función clave de las iglesias estructuradas (De la Mora, 2002: 36).

Por su parte, la secularización parece retomar un lugar importante entre los jóvenes, quienes propugnan la separación de los civil y lo religiosos, orillando en gran medida a la religión a un espacio de creencia personal, respaldando 
los valores laicos como elementos claves de la modernidad (Hervieu, 1991). Así, el derrumbamiento de la idea de una verdad global, que usualmente era la religiosa, parece ser cada vez más claro en ciertos lugares o espacios, como el académico, en donde la posmodernidad cuestiona las nociones e ideológicas heredadas, poniendo a prueba la pertinencia y racionalidad de lo que se cree, tanto de los individuos, las instituciones y la sociedad en general. De esta manera, parece que la globalización no muestra un futuro claro para las religiones hegemónicas del pasado, dando pauta a nuevas formas de religación con Dios, más cercanas e identificables con la diversidad promovida por la globalización (Hervieu, 1996).

Sin embargo, esta promoción de una globalización de la religión puede llevar consigo al desarrollo o modificación de elementos de identidad regional que vienen aunados a estas creencias, considerando que, en algunos casos, como el propuesto en el presente artículo, la identidad de la población de una región puede traer consigo claras referencias a elementos del imaginario religioso.

Entendemos por identidad a todo aquello que tiene que ver con la manera en que el un individuo o un grupo se definen a sí mismos, lo cual puede tener relación con una actitud, una cualidad, una preferencia o un valor (Vergara, 2011). Para la psicología, la identidad se entiende como el sentido propio de ser uno mismo, diferente a todos los demás. Se dice que la identidad puede ser consciente cuando la persona identifica esta diferencia con el resto del grupo, o bien inconsciente cuando no se tiene una distinción psíquica entre el yo y los demás sujetos u objetos externos (Galimberti, 2006).

Desde una percepción diferente, de un corte más filosófico, la identidad se ha relacionado con cuatro factores; la diferenciación de las categorías, la diferenciación de los individuos, la reidentificación del individuo y la identificación del mismo (Canto-Sperber, 2001). Claro está, que la mayoría de los académicos se han enfocado en buscar la identidad esencial del individuo, considerando como los cuatro factores como una parte esencial de esta identificación. Sin embargo, la identidad esencial de las personas, no es algo que pueda determinarse simplemente a partir del estudio del ser, ya que, en la mayoría de los casos, ésta se encuentra ligada de maneras diferentes, y con frecuencia de manera muy complicada, a la de los grupos a los que estas personas consideran pertenecer, o a los que los demás estiman que pertenecen (Aldana, 2013). Para Larraín (1996), el proceso de construcción 
La posibilidad de creencias religioso-regionales...

de identidad se debe entender como un proceso que incluye diversos elementos, como una superposición de tradiciones, pensamientos e ideologías provenientes de distintas partes.

En países como los latinoamericanos, laidentidad tiene un amplio significado, ya que incluye tanto bienes, como productos culturales, valores, artefactos, relatos, significaciones y categorías que les permiten diferenciarse y expresar la posesión de una idea de uno mismo consciente, comunicable y diferenciadora. El tener una historia común, imprime en los latinoamericanos la posibilidad de una identidad común, pero quealavezdifiereporlavariedady diversidad existenteentrecadaunadesus regiones.

La identidad deviene un desafío para las sociedades latinoamericanas y esto se debe a que su abordaje presenta tendencias contradictorias, que van desde aspectos metafísicos, hasta cuestiones culturales e individuales que enmarca lo que se entiende por ser nacional o ser latinoamericano (Roger \& Regalado, 2011).

Entre estos elementos de identidad, se encuentra un claro pasado enmarcado por la iglesia católica, la cual es evidente en la región y su población desde su nacimiento, con un ser, un vivir y un decidir constituido por una mezcla entre creencias tanto laicas como religiosas (Cipriani, 2015). Este es el sitio en el que la religión se constituye como un punto determinante de la identidad.

Las creencias religiosas contenidas en la religión, pueden ser consideradas como representaciones elaboradas por los seres humanos para afrontar y conjurar el azar, la incertidumbre, la angustia existencial y la muerte (Beyer \& Beaman, 2007). En sociedades, como la latinoamericana, la religión constituye un mecanismo a través del cual se legitima la significación de la realidad socialmente establecida. Durkheim (1982) ha mostrado como la religión es una representación del mundo en torno a lo que se fortalecen lazos de congregación social. La religión, en este contexto, construye una identidad colectiva sólida que impide la desintegración social, pero que, al mismo tiempo, inmuniza las consciencias individuales. Esta integración social se construye mediante la simbología común, siendo un elemento que desarrolla un sentimiento de comunidad. Así, es como la identidad religiosa se ha constituido como parte de la identidad regional latinoamericana, la cual se ha fortalecido o debilitado con el fenómeno globalizador. 


\subsection{La iglesia católica en el México actual.}

Ante esta nueva situación de competencia, de pérdida de espacios y de disminución de hegemonía, la iglesia católica se ha visto obligada a tomar serias medidas para contrarrestar los estragos y así evitar convertirse a mediano plazo en una ideología marginal (De la Torre, 2002). La experiencia de lo sucedido en Europa y la realidad religiosa de países como Brasil y Perú muestran el escenario de lo que podría suceder en México. Sin duda, una de las transformaciones más impactantes que se vive en Latinoamérica, a partir de las últimas décadas del siglo XIX, y con mayor aceleración en los últimos años, es el cambio de una sociedad católica a una sociedad plural religiosa (De la Mora, 2002: 37).

Aun así, y aunque podemos decir que México ha sido mayoritariamente católico desde los tiempos coloniales, durante las últimas décadas ha habido importantes transformaciones en el panorama religioso del país, pues, aunque hoy día la gran masa de los mexicanos sigue profesando la fe católica, no se puede subestimar el hecho de que cada vez existenmásofertasyadherentesaiglesiasomovimientos religiososqueno soncatólicos.

El censo de población de 1980 reveló que dos millones y medio de mexicanos pertenecían ya a denominaciones religiosas no católicas, lo cual aumentó un millón más, según los datos del siguiente censo en 1990 (Martínez, 1997). De este modo, se aprecia que la diversidad religiosa ya es un hecho irreversible en México pero que no resulta homogéneo en todo el país, sino que se observan características muy particulares en las distintas regiones. En el caso particular, las fronteras han sido las zonas con mayor cambio religioso, existiendo, sin embargo, diferencias importantes entre la frontera norte y la frontera sur (Odgers y De la Torre, 2004).

En el 2000, el censo reportó un $87.99 \%$ de población católica evidenciando una ligera pero constante reducción de creyentes católicos en el país. El censo también mostró que las tres iglesias de mayor presencia numérica, después de la católica, eran los Adventistas del Séptimo Día (con 488, 945 miembros), la Iglesia de Jesucristo de los Santos de los Últimos Días -mormones- (con 205, 229 practicantes) y Testigos de Jehová (con un millón 57, 736 creyentes).

El hecho de que cada vez menos mexicanos se consideren católicos habla de un importante cambio cultural que va de una sociedad basada en el monopolio de la religión católica, hacia una sociedad que tiende a diversificarse en términos de su filiación religiosa. Sin embargo, estos incrementos de la diversidad religiosa remiten a singularidades 
La posibilidad de creencias religioso-regionales...

regionales en los cuales están jugando un importante papel factores tales como la pobreza, la etnicidad, los aspectos rurales y urbanos, y la migración (Blancarte, 1992).

En el occidente, en cambio, las variaciones de la iglesia católica han sido más lento que en el resto del país, y aunque los fenómenos antes descritos están presentes, su impacto sigue siendo poco considerable. En los estados como Michoacán, Jalisco, Aguascalientes o Zacatecas, región que integra el llamado occidente de México, la disidencia al catolicismo es realmente marginal (con porcentajes que van 1.0 al 1.7\% del total), dejando claro que su pasado histórico sigue teniendo un claro peso en su población. La región occidente no solo ve a la Iglesia como parte de las creencias de su población, sino incluso, como una cuestión histórica, por ser la zona en donde mayor participación se dio durante la guerra cristera a principios del siglo XX (De la Torre y Gutiérrez, 2010).

Así pues, puede surgir un cuestionamiento cuando se aprecia esta diferencia entre lo que ha sucedido en la región occidente de México en comparación a otras zonas del país en temas religiosos: ¿Acaso el trasfondo histórico cultural podría impactar en el actuar o reaccionar de los fieles al momento de enfrentar las nuevas influencias del fenómeno globalizador?, ¿Será acaso que la religión en esta zona sigue siendo realmente la alternativa mejor argumentada o su pasado la vuelve en la más fuerte y por ende poco cuestionable?

Para poder aproximarnos a estas respuestas, es necesario que se comprenda como se estructuran los sistemas de creencias.

No se puede negar que los comportamientos de una sociedad son proporcionales al sistema de creencias que da argumento de sus decisiones, y que, por ende, es sumamente relevante el que cualquier análisis del actuar traiga consigo una deli2.3 Las creencias ante nuevos argumentos beración previa de lo que el agente considera como posible, adecuado o ideal para satisfacer sus deseos (Elster, 1983).

Con el fenómeno globalizador, mucha nueva información se encuentra al alcance de las personas, y con ello, un sin número de posibilidades de elección que antes ni siquiera consideraban. De tal manera, según Vázquez y Amézquita (2016), la mejor forma de comprender el posible actuar de un grupo social, como es el caso de los fieles de una religión, es llegar a precisar la posible modificación de su aba- 
nicodecreencias,yaqueestoabrelaposibilidadaunsinnúmerodeaccionesderivadas.

Como se ha señalado con anterioridad, la exposición que se tiene a nuevas formas de pensar, o a información ajena a lo que usualmente se cree, puede dar cabida a reacciones distintas ante una misma situación, y mientras en alguna región del país la llegada de movimientos religiosos alternos a la iglesia católica puede generar un cuestionamiento a las viejas ideologías, en áreas como la región occidente, puede ser un motivo adicional para aferrarse a lo que se cree como propio o inclusive característico de la zona. Sin embargo, si nuestras creencias no se encuentran bien argumentadas, lo óptimo de los comportamientos puede ser altamente cuestionable (Vázquez, Campos y Torijano, 2017).

Ante esta situación cabria la necesidad de comprender la forma en que se estructuran las creencias, ya que el cuestionamiento inicial de este apartado se sustenta en ello. Para Elster (Elster, 2010), las creencias son estructuras ideológicas construidas a partir de argumentos, mismos que se presume, permiten que el agente se acerque a aquello que considera mejor para la satisfacción de sus deseos. Para este sociólogo, no cualquier información consigue estructurar creencias en los individuos, ya que, si lo que se lee, escucha o aproxima no resulta ser realmente una alternativa para el agente, esto se desecha, pudiendo incluso fortalecer viejas creencias que se considera siguen siendo valiosas, óptimas o efectivas (Elster, 1997).

En el caso de la religión, el fenómeno globalizador parece aproximar a las personas a un gran cumulo de información relacionada con el desarrollo de la fe, sin embargo, si el fiel no ve en esta información una verdadera alternativa, no hay motivo para cuestionar aquello que ya se considera bien argumentado.

Si a lo que se conoce sobre un tema, se le suma una argumentación histórica, un aparejamientoconvalores propiosdelaregión, oincluso, unposibleorgulloregionalasimbologíasreligiosas, haypocasposibilidadesdedarcabidaanuevossistemasdecreencias. Algo que puede apreciarse en el occidente mexicano, es el hecho de que la iglesia católica ha cedido muy poco espacio sobre el poder e influencia que llega a tener en la sociedad de la región, variando muy poco de lo que llegaba a ser en la época colonial a pesar de haber pasado varios siglos desde ello. Festividades religiosas claramente arraigadas a la historia de sus municipios, influencia social e incluso política de los altos clérigos y un posicionamien territorial 
La posibilidad de creencias religioso-regionales...

clave en los primeros cuadros de las ciudades, hacen que lo que en un inicio pareciera un tema de ideologías religiosas, llegue a constituirse en una cuestión de creencias que respaldan el actuar de una región entera.

Este análisis, permite comprender por qué la gran metrópolis de Guadalajara, es constantemente valorada como una ciudad costumbrista, lo cual no necesariamente se relaciona por su apego a los valores o ideologías de su pasado, sino más bien, por la clara influencia que la Iglesia continúa teniendo en las decisiones que se toman entre su población o incluso sus gobernantes.

Pero, ¿Qué ha llevado a que las creencias religiosas de la región occidente de México sigan teniendo tanta fuerza, mientras que las de otras zonas como la frontera o el centro del país ceden espacio a nuevos sistemas de creencias?, ¿Acaso la Arquidiócesis de Guadalajara ha conseguido aprovechar su posición e historia como elemento constitutivo de creencias religioso-regionales?

\subsection{La respuesta del arquidiócesis de Guadalajara ante las nuevas creencias globalizantes.}

En Guadalajara, principal centro jerárquico de la iglesia católica en el occidente, la transformación en el ámbito religioso se ha experimentado como una recomposición de lo religioso, siendo esta transformación de lo sagrado en la sociedad una forma de responder a la modernidad (Hernández, 2000). Tanto la globalización, con las nuevas tecnologías e intercambios ideológicos, como la secularización y el creciente individualismo, están transformando el panorama religioso local en las últimas décadas (Connaughton, 1992). El internet, por ejemplo, ha puesto al alcance de cada vez más habitantes de la zona metropolitana de Guadalajara (ZMG) el conocimiento, intercambio y difusión de múltiples ideas en materia religiosa, lo cual ha incrementado y facilitado la proliferación de un mercado de bienes simbólicos de salvación espiritual y de salud física (De la Torre y Gutiérrez, 2010). En cuanto a la secularización, en la ZMG, ésta se ha expresado no bajo la interpretación convencional de abandono de la religión o del predominio del laicismo en diversas esferas de la vida pública y privada, sino que tiende a manifestarse en la emergencia de la subjetividad religiosa como criterio de orientación y como un sentido alterno a la pertenencia institucional (De la Mora, 2002). 
El individualismo, por su parte, se ha manifestado más en la subjetividad religiosa personal con respecto a la moral privada y no tanto en el sentido de la moral social. Existe de hecho una clara disidencia de los grupos más jóvenes en cuanto a la doctrina moral propuesta por la iglesia católica que se hace evidente en la amplia aceptación del uso de anticonceptivos, por ejemplo, y en el pleno debate de temas como el aborto, la homosexualidad y la eutanasia (Bárcenas, 2014). Existe también una creciente disociación entre la pertenencia formal a la Iglesia y la plena identificación con dogmas y prácticas dentro del catolicismo local (Martínez, 1997). En este sentido, se puede decir que la identidad católica de los creyentes se vive más como una norma que como una identidad de elección (Hernández, 2000).

Así pues, y a pesar de los cambios experimentados últimamente, algunos de los estudios más recientes muestran que Guadalajara sigue siendo una sociedad tradicional, considerada además como un bastión del catolicismo en el centro occidente de México y con creciente importancia a un nivel mundial (De la Torre, Dorantes, Fortuny y Gutiérrez, 1997). Sin embargo, tal pareciera que desde hace algunos años la mayoría de los creyentes se hallaran en un momento de impasse en la construcción de sus identidades frente a la diversidad de ofertas de salvación y sus comportamientos para resolver problemas prácticos de su vida cotidiana (Martínez, 1997). A pesar de que muchos ciudadanos de la zona no se encuentran plenamente convencidos de los argumentos que les da la religión sobre temas que impactan su vida diaria, siguen adoptando una postura católica ante las situaciones que se les presentan, al considerar que esto más que ser algo religioso, también resulta algo propio del ser tapatío, zapopano o de algún municipio de occidente.

Como respuesta a esta disociación, posible diferencia de ideologías o incluso, debilidad de argumentos, la iglesia católica ha elegido a la región occidente de México como centro de importantes eventos que promueven la doctrina de la fe, como fue el caso del Congreso Eucarístico Internacional (CEI) en el 2004, el cual pocas veces se ha dado fuera de Europa (Ramos, 2004). La elección de Guadalajara como sede del CEI, en lugar de la Ciudad de México, no fue fortuita, pues los rasgos de preeminencia católica a nivel nacional de esta región la hacen un espacio singular los objetivos del Congreso, entre los que se encontraba afianzar el dogma de la Eucaristía, reforzar las prácticas comunitarias católicas y, en particular, presentar un ejercicio de fuerza frente a las llamadas "sectas" (Gutiérrez, 2004). 
La posibilidad de creencias religioso-regionales...

Este evento estuvo enmarcado en un entorno de amplia difusión mediática, tanto tradicional como electrónica, contando con una gran cobertura de todos los actos importantes durante toda la semana en que se llevó a cabo (Arquidiócesis de Guadalajara, 2004). De manera adicional a toda esta información, el Congreso coincidía con la tradicional romería de Nuestra señora de Zapopan, uniendo así, el objetivo del evento, con tradiciones locales propias a las que la población, sea religiosa o no, se siente arraigado en la región.

El CEI concluyó con una celebración masiva en el Estadio Jalisco, en donde por medio de pantallas gigantes se observó y escucho un mensaje de Juan Pablo II emitido en vivo desde la ciudad de Roma. A nivel internacional, la Iglesia califico el evento como excepcional, enalteciendo la fe y compromiso de los fieles católicos de México, aunque de manera especial, de la Zona Metropolitana de Guadalajara (Arquidiócesis de Guadalajara, 2004). De tal forma, un evento plenamente religioso, se convirtió en un orgullo para la región, consiguiendo que nuevamente los argumentos religiosos se conjugaran con el ideario propio de la zona.

\section{Consideraciones finales}

La globalización y los fenómenos que le acompañan en el mundo posmoderno actual están transformando todos los ámbitos de la vida humana, no sólo en el aspecto económico como a veces se señala. La religión y las prácticas religiosas no han sido la excepción. Tanto la globalización como la secularización y el individualismo han sido factores importantes en los cambios religiosos globales y locales. Sin embargo, existen casos en los que estos cambios parecieran no impactar de la misma manera, consiguiendo que las creencias con un pasado histórico y un respaldo moral, sigan conservando su vitalidad y uso, aún en la época contemporánea. La arquidiócesis de Guadalajara, es un ejemplo de lo anteriormente señalado, ya que, a pesar de encontrarse con sede en una de las ciudades de mayor crecimiento de Latinoamérica, ha podido conservar en sus fieles un interés y respaldo hacia los valores morales católicos, viéndose poco afectada por la presencia de otras influencias ideológicas o propuestas religiosas.

El presente artículo, ha buscado dar luz al impacto que puede tener un antecedente histórico, que relaciona ideologías religiosas y regionales en un mismo pasado, al momento de enfrentar la llegada de información alternativa en momentos de globalización como los que se viven actualmente en Latinoamérica 
Esto da cabida a que la religión pueda llegar a ser vista más allá de un camino a Dios, sino también como parte del ideario de una región. Lo planteado en este artículo, permite dar los primeros pasos en cuanto a estudios de creencias religioso-regionales, aspecto que queda abierto para investigaciones posteriores. De esta forma, los agentes católicos de Guadalajara, no solo ven en la moral de la Iglesia parámetros que regulan su fe, sino también, aspectos que integran su forma de actuar como católicos, tapatíos y mexicanos de la región occidente.

\section{Refrencias}

Aldana, C. (2013). Identidad. Ciencias Holguín, 1-10.

Arquidiócesis de Guadalajara. (2004). 48 CONGRESO EUCARÍSTICO. Obtenido de "La Eucaristía, luz y vida: http://www.vatican.va/roman_curia/ pont_committees/eucharist-congr/documents/rc_committ_euchar_doc_20021009_48-cong_sp.html

Bárcenas, K. (2014). Iglesias y grupos espirituales para la diversidad sexual y de género en México: Intersecciones sobre religión y género. Revista de Estudios Sociales(49), 22-46.

Bauer, A. (1986). La Iglesia en la economía de América Latina: Siglos XVI al $X I X$. México: INAH.

Bautista, C. (2005). Hacia la romanización de la Iglesia mexicana a fines del siglo XIX. Historia Mexicana, LV(217), 99-144.

Blancarte, R. (1992). Historia de la Iglesia Católica en México. México: Fondo de Cultura Económica.

Beyer, P., \& Beaman, L. (2007). Religion, Globalización and Culture. Boston: Brill.

Canto-Sperber, M. (2001). Diccionario de ética y de filosofía moral. México: Fondo de cultura económica. 
La posibilidad de creencias religioso-regionales...

Cipriani, R. (2015). Religión difsa en américa latina. Sociedad y religión: Sociología, Antropología e Historia de la Religión en el Cono Sur, XXV(44), 269-278

Connaughton, B. (1992). Ideología y sociedad en Guadalajara. México: Universidad Nacional Autónoma de México.

De la Mora, R. (2002). Posmodernidad e ideologias religiosas:. En K. Covarrubias y R. De la Mora, Cambios religiosos globales y reacomodos locales. Colima: ANUIES.

De la Torre, R. (1995). Los hijos de la luz. Discurso, identidad y poder en La Luz del Mundo. Guadalajara: ITESO.

De la Torre, R. (2002). Guadalajara y su región: cambios y permanencias en la relación religión-cultura-territorio. En K. Covarrubias y R. De la Mora, Cambios religiosos globales y reacomodos locales (pág. 45). Colima: ANUIES Occidente.

De la Torre, R. y Gutiérrez, C. (2010). El campo religioso cristiano en Guadalajara: Una cronología del siglo XX. En C. Gutiérrez, Discursos hegemónicos e identidades invisibles en el Jalisco posrevolucionario (págs. 159-226). Zapopan: El Colegio de Jalisco.

De la Torre, R., Dorantes, A., Fortuny, P. y Gutiérrez, C. (1997). Tradición religoosa y secularizaicón en Guadalajara. Eslabones(14).

Durkheim, E. (1982). Las formas elementales de la vida religiosa. Madrid: Akal.

Elster, J. (1983). Uvas Amargas. Sobre la subversión de la racionalidad. Barcelona: Peninsula.

Elster, J. (1997). Estudios sobre la racionalidad. Lectura pronunciada en la ceremonia en que se le concedía el título de Doctor Honoris Causa por la Universidad de Valencia. Valencia. 
Elster, J. (2010). La explicación del comportamiento social: mas tuercas y tornillos para las ciencias sociales. Barcelona: Gedisa.

Galimberti, U. (2006). Diccionario de Psicología. México: Siglo XXI Editores.

González, L. (1983). Peculariedades historicas del Oeste Mexicano. Encuentro.

González, L. (1983). Peculiaridades históricas del Oeste Mexicano. Encuentro, $1(1), 15$.

Gutiérrez, J. (2004). Las sectas. Dolor de cabeza para El Vaticano. Milenio(365). Hernández, M. (2000). Reseña del libro: Creyentes y creencias en Guadalajara. Revista Relaciones, XXI(83).

Hervieu, D. (1991). Secularización, modernidad y cambio religioso. En E. Luengo, Secularización, modernidad y cambio religioso (págs. 83-101). México: Universidad Iberoamericana.

Hervieu, D. (1996). Por una sociología de las nuevas formas de religiosidad: algunas cuestiones teóricas previas. En G. Giménez, Identidades religiosas y sociales en México (págs. 23-45). México: UNAM.

Larraín, J. (1996). Modernidad, razón e identidad en América Latina. . Santiago de Chile: Andrés Bello.

Martínez, C. (1997). ¿Existe la diversidad religiosa en México. Eslabones(14).

Miranda, L. (2007). La iglesia católica en las más recientes histografías de México y Argentina. Religión, modernidad y secularización. Historia Mexicana, LVI(4), 1393-1426.

Odgers, O. y De la Torre, R. (2004). Cartografías del cambio religioso en México (1950-2000). En C. Gutiérrez, El fenómeno religioso en el occidente de México. Guadalajara: El Colegio de Jalisco / Universidad de Guadalajara. 
La posibilidad de creencias religioso-regionales...

Ramos, V. (2004). Pierde poder la Iglesia Católica. Milenio(13).

Roger, E., \& Regalado, C. (2011). Reflexiones sobre la identidad. Ciencias Sociais Unisinos, 47(1), 98-100.

Semanario. (16 de octubre de 2004). Periódico Semanario. Órgano de formación y difusión de la Arquidiócesis de Guadalajara. , pág. 10.

Vázquez, J. C. y Amézquita, J. A. (2016). Una aproximación Elsteriana del Terrorismo Racional. Revista de Ciencias Sociales(152), 107-116.

Vázquez, J. C., Campos, C. F. y Torijano, O. (2017). Aproximación interdisciplinaria a las reminiscencias del discurso de castas colonial en México. Revisa de El Colegio de San Luis, VII(13), 202-221.

Vergara, F. (2011). Identidad religiosa latinoamericana: El sustrato católico. UCMaule Revista Académica(40), 96-112.

Villar, J. (2001). La Iglesia, el ecumenismo y las religiones no cristianas. Anuario de Historia de la Iglesia(10), 225-238.

\section{¿Cómo citar este artículo?}

Coss y León Coss y León, D. y Vázquez Parra, J. (Enero-junio, 2018). La posibilidad de creencias religioso-regionales. Una aproximación desde el significado de la religión católica en el Occidente de México. Revista humanidades, 8(1), 121-136. doi: http://dx.doi.org/10.15517/h.v8i1.31865 